\title{
Localization of Cardiac Myosin-Specific Antibody in
}

\section{Myocardial Infarction}

\author{
Ban An Khaw, George A. Beller, Edgar Haber, and Thomas W. Smith \\ From the Cardiac Unit, Massachusetts General Hospital, and the Department \\ of Medicine, Harvard Medical School, Boston, Massachusetts 02114
}

A в S T R A C T Specific localization of purified antibody against cardiac myosin has been demonstrated in areas of altered myocardial membrane permeability after experimental myocardial infarction. Intravenously administered radioiodine-labeled antimyosin was selectively localized in infarcted myocardium of seven dogs $24 \mathrm{~h}$ after coronary occlusion. The mean ratio $( \pm S E)$ of antimyosin antibody in infarcted to normal myocardium in the center of the infarct was $4.2 \pm 0.4$ for endocardial and $2.9 \pm 0.3$ for epicardial layers. By utilizing $\left(\mathrm{Fab}^{\prime}\right)_{2}$ fragments of antimyosin obtained by pepsin digestion of purified antibody, the ratio of uptake was increased in eight dogs to $6.1 \pm 0.6$ in the endocardial and 3.3 \pm 0.4 in the epicardial layers at the infarct center $24 \mathrm{~h}$ after occlusion. These ratios were further increased in the infarct center to $13.8 \pm 1.2$ in the endocardial and $7.3 \pm 0.8$ in the epicardial layers when eight dogs were sacrificed $72 \mathrm{~h}$ after coronary occlusion.

The specificity of antimyosin $\left(\mathrm{Fab}^{\prime}\right)_{2}$ localization in infarcted myocardium was demonstrated in four dogs by simultaneous intravenous administration of ${ }^{120} \mathrm{I}$-labeled antimyosin $\left(\mathrm{Fab}^{\prime}\right)_{2}$ and ${ }^{131}$ I-labeled normal rabbit gamma globulin $\left(\mathrm{Fab}^{\prime}\right)_{2}$. Nonspecific trapping of normal rabbit IgG $\left(\mathrm{Fab}^{\prime}\right)_{2}$ was observed to be about $38 \%$ of total antimyosin $\left(\mathrm{Fab}^{\prime}\right)_{2}$ uptake in the central zone of infarction.

Regional blood flow was related to antimyosin $\left(\mathrm{Fab}^{\prime}\right)_{2}$ uptake in infarcted myocardium by utilizing simultaneous administration of ${ }^{85} \mathrm{Sr}$-labeled microspheres. An inverse exponential relationship between antimyosin $\left(F^{\prime} b^{\prime}\right)_{2}$ uptake and regional blood flow was observed $(r=0.85)$. The specific localization of antimyosin

Dr. Khaw was supported by research fellowship 1312-F from the American Heart Association, Massachusetts Affiliate, and the American Heart Association, Northeast Massachusetts Chapter.

Received for publication 3 November 1975 and in revised form 26 March 1976. antibody or its $\left(\mathrm{Fab}^{\prime}\right)_{2}$ components in infarcted myocardium suggests a conceptually new approach to myocardial infarct localization and sizing.

\section{INTRODUCTION}

After acute myocardial infarction, there is an increase in permeability of the myocardial cell membrane, resulting from ischemic damage. This allows the egress into the plasma of intracellular macromolecular constituents such as creatine phosphokinase (1), serum glutamate oxalacetate transaminase (2), and lactate dehydrogenase (3), as well as cations such as potassium (4). This ischemia-induced increase in permeability of damaged myocardial cell membranes should also allow the inward diffusion of other macromolecules.

The purpose of this investigation was to determine whether radioiodine-labeled antibody to cardiac myosin or its $\left(F_{a b}\right)_{2}$ fragments would localize specifically in infarcted myocardium in vivo. In this communication, we report the specific and selective localization of cardiac myosin-specific antibody and $\left(F^{\prime} b^{\prime}\right)_{2}$ fragments in infarcted myocardium and relate this localization to the severity and duration of ischemia.

\section{METHODS}

Extraction of cardiac myosin. Cardiac myosin was isolated from canine left ventricular myocardium according to the procedure of Katz et al. (5). Myosin was further purified by ammonium sulfate precipitation (37-42\% saturation) as described by Wikman-Coffelt et al. (6). The myosin obtained was solubilized in $0.5 \mathrm{M} \mathrm{KCl}$, then dialyzed against 40 vol of $0.15 \mathrm{M}$ potassium phosphate, $\mathrm{pH} 7.5,10 \mathrm{mM}$ (EDTA) for $24 \mathrm{~h}$. Particulate materials were removed by centrifugation at $100,000 \mathrm{~g}$ for $30 \mathrm{~min}$ at $4^{\circ} \mathrm{C}$. Homogeneity of myosin was determined by sodium dodecyl sulfate gel electrophoresis in a discontinuous buffer system as described by Neville (7), with $10 \%$ acrylamide gels. The preparation was found to have two myosin light and one myosin heavy chain bands and slight traces of actin. 


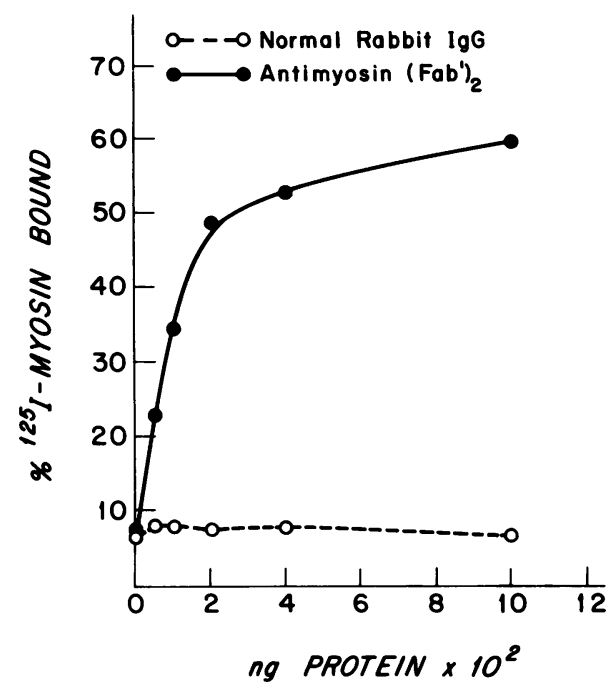

FIGURE 1 Antibody activity of purified antimyosin $\left(\mathrm{Fab}^{\prime}\right)_{2}$ fragments. The antibody activity is represented by the percent of total ${ }^{125} \mathrm{I}$-myosin bound by antimyosin $\left(\mathrm{Fab}^{\prime}\right)_{2}$ fragments (-—) and by control normal rabbit IgG ( $\mathrm{O}-$ $-\mathrm{O})$, at various concentrations of antimyosin $\left(\mathrm{Fab}^{\prime}\right)_{2}$ protein (horizontal axis).

Immunization procedures. Purified canine cardiac myosin $(0.5 \mathrm{mg} / \mathrm{ml})$ was emulsified in an equal volume of complete Freund's adjuvant and injected intradermally and into the toe pads of three New Zealand white rabbits by the schedule of Lawrence et al. (8). The primary immunization consisted of $500 \mu \mathrm{g}$ of canine cardiac myosin per rabbit, followed 3 wk later by secondary immunization with 400 $\mu \mathrm{g}$ of myosin. At the 5th wk, a booster injection of $300 \mu \mathrm{g}$ was given. 1 wk later, $50 \mathrm{ml}$ of blood was obtained from each animal by ear artery incision. Weekly bleedings were subsequently obtained, and booster injections of $500 \mu \mathrm{g}$ myosin/animal in complete Freund's adjuvant were administered intradermally monthly for $12 \mathrm{mo}$.

Determination of antibody activity. Antisera to canine cardiac myosin were tested initially for antibody content by double immunodiffusion with $1 \%$ agarose in $50 \mathrm{mM}$ potassium phosphate, $\mathrm{pH} 7.5$, and $0.15 \mathrm{M} \mathrm{NaCl}$ (9). The antibody activity of purified antimyosin or its $\left(\mathrm{Fab}^{\prime}\right)_{2}$ fragments was determined by the binding capacity of the antibody for iodine-125-labeled canine cardiac myosin ${ }^{125} \mathrm{I}-$ myosin) prepared according to the lactoperoxidase method of Marchalonis (10). Normal rabbit IgG (Pentex Biochemical, Kankakee, Ill.) was used as a nonimmune control. To $10-\mu 1$ samples (approximately $0.5 \mathrm{ng} / 10 \mu \mathrm{l}$ ) of ${ }^{125} \mathrm{I}-$ myosin, each containing approximately $20,000 \mathrm{cpm}$, various concentrations of antibody or $\left(\mathrm{Fab}^{\prime}\right)_{2}$ fragments were added. The reactants were incubated at $37^{\circ} \mathrm{C}$ for $1 \mathrm{~h}$ in $100 \mu \mathrm{l}$ of $1 \%$ bovine serum albumin $(B S A)^{1}$ (Pentex) in $0.3 \mathrm{M} \mathrm{Na}$ phosphate, $0.15 \mathrm{NaCl}$ (phosphate-buffered saline, $\mathrm{PBS}$ ), $\mathrm{pH}$ 7.0. Unlabeled carrier normal rabbit IgG (Pentex) (20 $\mu \mathrm{g} /$ tube) was added, followed by $0.5 \mathrm{ml}$ of $1: 5$ dilution of goat anti-rabbit IgG serum (Pentex, lot 16). After a 1-h incubation at $37^{\circ} \mathrm{C}$, the precipitates were centrifuged for 15 min at $5,000 \mathrm{~g}$ at $4^{\circ} \mathrm{C}$. The precipitate from each tube was

${ }^{1}$ Abbreviations used in this paper: BSA, bovine serum albumin; PBS, phosphate-buffered saline. washed in $1 \mathrm{ml}$ of $0.3 \mathrm{M}$ PBS. Radioactivities in the precipitates and supernatant solutions were determined by counting in a gamma well scintillation spectrometer ( $\mathrm{Nu}$ clear-Chicago Corp., Des Plaines, Ill., model 1085). Percent of ${ }^{125} \mathrm{I}$-myosin bound at various antimyosin $\left(\mathrm{Fab}^{\prime}\right)_{2}$ concentrations for a representative preparation is illustrated in Fig. 1, as calculated from the following expression: $\%$ bound $=[(\mathrm{cpm}$ in precipitate $) \times 100 /(\mathrm{cpm}$ in precipitate $)$ $+(\mathrm{cpm}$ in supernatant solution $)]$.

No interspecies cross-reactivity was observed between rat cardiac myosin and rabbit anticanine cardiac myosin serum. However, cross-reactivity was observed between rabbit anticanine cardiac myosin serum and canine skeletal muscle myosin. A $50 \%$ inhibition of maximum binding of ${ }^{125} \mathrm{I}-$ labeled canine cardiac myosin by anticanine cardiac myosin serum (at $1: 100$ dilution) required 2.5 times more canine skeletal muscle myosin by weight than homologous canine cardiac myosin.

Purification of cardiac myosin-specific antibody. Rabbit antibody specific for canine cardiac myosin was purified by affinity chromatography with a myosin-Sepharose immunoadsorbent, prepared by coupling purified canine cardiac myosin to cyanogen bromide-activated agarose (Sepharose-4B, Pharmacia Fine Chemicals, Inc., Piscataway, N. J.) by the general method described by Cuatrescasas (11). The immunoadsorbent was equilibrated in $30 \mathrm{mM} \mathrm{KCl}, 25 \mathrm{mM}$ Tris$\mathrm{HCl}, \mathrm{pH}$ 7.5, $1 \mathrm{mM}$ EDTA (Tris-buffer).

To a $50-\mathrm{ml}$ sample of rabbit anticanine cardiac myosin serum, $25 \mathrm{ml}$ of saturated ammonium sulfate solution were added with constant stirring to give a final $33 \%$ saturation. The precipitate was separated by centrifugation at $10,000 \mathrm{~g}$ for $15 \mathrm{~min}$ at $4^{\circ} \mathrm{C}$, then dissolved in Tris buffer and dialyzed against 40 vol of Tris buffer at $4^{\circ} \mathrm{C}$ for $24 \mathrm{~h}$. The protein solution containing the antimyosin antibody was then chromatographed on the myosin-Sepharose immunoadsorbent. After application of the sample, the column was washed with Tris buffer until the eluate showed no absorbance at $280 \mathrm{~nm}$. Myosin-specific antibody was then desorbed with $5 \mathrm{M}$ guanidine- $\mathrm{HCl}$. Fractions containing the antibody were pooled and then dialyzed against $40 \mathrm{vol}$ of Tris-buffer at $4^{\circ} \mathrm{C}$ for $24 \mathrm{~h}$. Small amounts of insoluble material were removed by centrifugation at $10,000 \mathrm{~g}$ for $30 \mathrm{~min}$ at $4^{\circ} \mathrm{C}$. The supernatant solution was then concentrated by vacuum dialysis to approximately $2 \mathrm{mg} / \mathrm{ml}$ as determined by absorbance at $280 \mathrm{~nm}$. The antimyosin antibody solution was stored at $-20^{\circ} \mathrm{C}$. The elution profile of a typical affinity chromatography run on $2.5 \times 70-\mathrm{cm}$ myosin-Sepharose column is shown in Fig. 2.

Preparation of $\left(F a b^{\prime}\right)$, fragments. Antimyosin antibody purified by affinity chromatography was subjected to hog pepsin (Sigma Chemical Co., St. Louis, Mo.) digestion at $37^{\circ} \mathrm{C}$ for $20 \mathrm{~h}$ at an enzyme-to-substrate concentration ratio of $1: 100$, according to the procedure described by Edelman and Marchalonis (12). At the end of the incubation, the reaction mixture was centrifuged at $10,000 \mathrm{~g}$ for $30 \mathrm{~min}$. The supernatant solution was then submitted to Sephadex G-100 (Pharmacia) column chromatography $(2.5 \times 70 \mathrm{~cm})$ Intact antimyosin antibody and protein aggregates were eluted in the void volume. The first protein peak to be eluted in the included volume, comprising approximately $80-90 \%$ of the total protein applied to the column, contained the $\left(\mathrm{Fab}^{\prime}\right)_{2}$ components of antimyosin antibody, concentrated by vacuum dialysis to approximately $2 \mathrm{mg} / \mathrm{ml}$, as described previously.

$\left(\mathrm{Fab}^{\prime}\right)_{2}$ fragments of normal rabbit gamma globulin were also prepared as described above. 
Radioiodination. Radioiodination of intact antimyosin antibody, its $\left(\mathrm{Fab}^{\prime}\right)_{2}$ fragments, and $\left(\mathrm{Fab}^{\prime}\right)_{2}$ fragments of normal rabbit IgG was performed by the lactoperoxidase procedure of Marchalonis (10). Carrier-free ${ }^{125} \mathrm{I}$ (New England Nuclear, Boston, Mass.) was used for the iodination of intact antimyosin antibody and $\left(\mathrm{Fab}^{\prime}\right)_{2}$ fragment preparations. ${ }^{181} \mathrm{I}$, also carrier-free, was used to iodinate $\left(\mathrm{Fab}^{\prime}\right)_{2}$ fragments of normal IgG by the same method. Covalently bound labeled iodine was separated from free radioiodine by Sephadex G-25 gel permeation chromatography on a $0.5 \times 10 \mathrm{~cm}$-column precoated with $1.5 \mathrm{ml}$ of $1 \% \mathrm{BSA}$ in $0.3 \mathrm{M}$ PBS to reduce nonspecific binding of radioiodinated antibody to the column matrix. Radioiodinated proteins were eluted in the void volume, and were stored at $-20^{\circ} \mathrm{C}$. The specific activity of radioiodinated antimyosin antibody or its $\left(\mathrm{Fab}^{\prime}\right)_{2}$ fragments was approximately $130 \mathrm{Ci} / \mathrm{mM}$.

Experimental myocardial infarct model. 30 mongrel dogs $(19-22 \mathrm{~kg})$ were anesthetized with intravenous pentobarbitol $(30 \mathrm{mg} / \mathrm{kg})$ after which a left thoracotomy was performed under sterile conditions. Acute myocardial infarction was produced by the method described by Beller et al. (13). Confluent branches of the left anterior descending coronary artery were ligated $5 \mathrm{~min}$ apart until approximately $30-50 \%$ of the anterolateral wall appeared cyanotic. Coronary venous branches remained intact. Any dogs developing ventricular fibrillation $(10 \%)$ were not included in the study. An indwelling canula was inserted in the left atrium via a stab wound in the left atria appendage in those dogs receiving microspheres for regional blood flow determination. The thoracotomy was then closed and the animals were allowed to recover from anesthesia. All animals alive for more than $24 \mathrm{~h}$ received a $250-\mathrm{mg}$ daily dose of ampicillin. All these animals appeared healthy and active during recovery. The left atrial catheter was flushed several times daily with heparinized saline.

Localization of whole antimyosin antibody or its $\left(F a b^{\prime}\right)$, fragments. Radioiodinated antimyosin antibody or $\left(\mathrm{Fab}^{\prime}\right)_{2}$ fragments were administered intravenously $4 \mathrm{~h}$ after coronary occlusion in 23 dogs. Each animal received $100 \mu \mathrm{Ci}$ of intact antimyosin antibody or $\left(\mathrm{Fab}^{\prime}\right)_{2}$ fragments, injected through a disposable Swinnex-13 filter unit $(0.22 \mu \mathrm{m}$ pore size; Millipore Corp., Bedford, Mass.), preflushed with 5 $\mathrm{ml}$ of $1 \% \mathrm{BSA}$ in $0.3 \mathrm{M}$ PBS. The amount of radioactive protein received by each animal was less than $100 \mu \mathrm{g} .24 \mathrm{~h}$ after coronary occlusion, animals were sacrificed and myocardial samples $(0.5-1.0 \mathrm{~g})$ from epicardial and endocardial layers of the center and periphery of the infarct, the adjacent border zone region, and normal posterior left ventricular myocardium were obtained. Concentration of radioiodinated material in each sample was determined by gamma scintillation counting and counts per minute per gram wet weight of the samples were calculated. In another group of eight dogs that had received iodine-125-labeled antimyosin $\left(\mathrm{Fab}^{\prime}\right)_{2}$ fragments, antibody uptake in infarcted myocardium was determined $72 \mathrm{~h}$ after coronary occlusion as described above.

The relative antimyosin antibody or $\left(\mathrm{Fab}^{\prime}\right)_{2}$ concentration $\left(\left[A b_{1}\right] /\left[A b_{N}\right]\right)$ in these samples was calculated as the ratio of ${ }^{100} \mathrm{I}$ labeled antimyosin antibody or $\left(\mathrm{Fab}^{\prime}\right)_{2}$ in the infarcted myocardium (I) to that present in normal posterior left ventricular myocardium $(\mathrm{N})$.

Specific localization of antimyosin $\left(F a b^{\prime}\right)$, in infarcted myocardium. In another group of four experimentally infarcted dogs, $100 \mu \mathrm{Ci}$ each of ${ }^{125} \mathrm{I}$-labeled antimyosin $\left(\mathrm{Fab}^{\prime}\right)_{2}$ fragments and iodine-131-labeled normal rabbit IgG $\left(\mathrm{Fab}^{\prime}\right)_{2}$

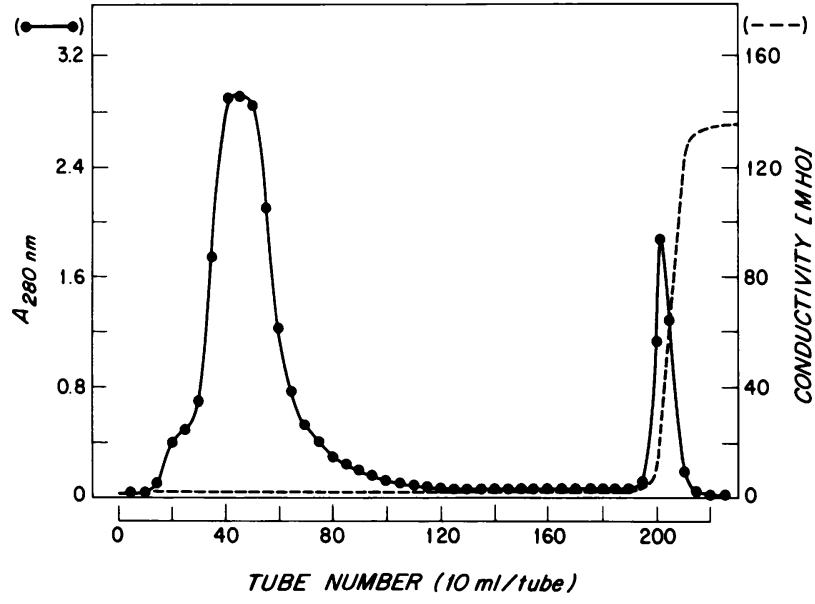

FIGURE 2 Elution profile in the purification of canine cardiac myosin-specific antibody by myosin-Sepharose affinity chromatography (,$- \mathrm{A}_{280 \mathrm{~nm}}$ ). Canine cardiac myosinspecific antibody was desorbed with $5 \mathrm{M}$ guanidine $\mathrm{HCl}$, elution of which is indicated by rise in conductivity (-.-).

fragments were simultaneously administered i.v. $4 \mathrm{~h}$ after coronary occlusion. 48-72 h later, the animals were sacrificed, and ${ }^{125} \mathrm{I}$ and ${ }^{181} \mathrm{I}$ activities in multiple myocardial tissue samples were determined by differential spectrometry. The specific localization of antimyosin $\left(\mathrm{Fab}^{\prime}\right)_{2}$ fragments was calculated as the difference between relative antimyosin $\left(F_{a b}^{\prime}\right)_{2}$ concentration and relative normal IgG $\left(F_{a b}^{\prime}\right)_{2}$ concentration in the same tissue sample, by the following equation: specific localization $=\left(\left[\mathrm{Ab}_{\mathrm{I}}\right] /\left[\mathrm{Ab}_{\mathrm{N}}\right]\right)-\left(\left[\mathrm{IgG}_{\mathrm{I}}\right] /\right.$ [IgGN]).

Relationship between regional myocardial blood flow and specific antimyosin $\left(F a b^{\prime}\right)$ \& uptake. Regional myocardial blood flow and iodine-125-labeled antimyosin $\left(\mathrm{Fab}^{\prime}\right)_{2}$ uptake were simultaneously assessed in four dogs that underwent coronary occlusion for $24 \mathrm{~h} .100 \mu \mathrm{Ci}$ of ${ }^{125}$ I-labeled antimyosin $\left(\mathrm{Fab}^{\prime}\right)_{2}$ were administered as described previously. $15 \mathrm{~min}$ before sacrifice, a bolus of $4 \times 10^{\circ}$ carbonized microspheres (15 $\pm 5 \mu \mathrm{m}, 3 \mathrm{M}$ Co., St. Paul, Minn.) labeled with strontium-85 was injected into the left atrium via the indwelling canula. Microsphere distribution and antimyosin $\left(\mathrm{Fab}^{\prime}\right)_{2}$ uptake were obtained by differential spectrometry in myocardial samples from infarct, border, and nonischemic zones. A similar protocol was carried out in another group of four infarcted dogs sacrificed $72 \mathrm{~h}$ after coronary occlusion.

Statistical analysis. Statistical differences between ischemic and nonischemic values were assessed by paired $t$ test (14). In studies involving comparison of relative antibody uptake to regional blood flow, linear regression curves relating antibody uptake to flow were obtained by utilizing $y=a+b x$, where $y=\log _{10}$ (percent normal myocardial blood flow), and $x=$ relative antibody uptake. Constants $a$ and $b$ were obtained by the method of Snedecor and Cochran (14).

\section{RESULTS}

Localization of ${ }^{125}$ I-labeled antimyosin antibody in infarcted myocardium. Relative localization of ${ }^{125} \mathrm{I}-\mathrm{la}-$ beled antimyosin antibody in central and peripheral zones of infarction and in the border zone region in 


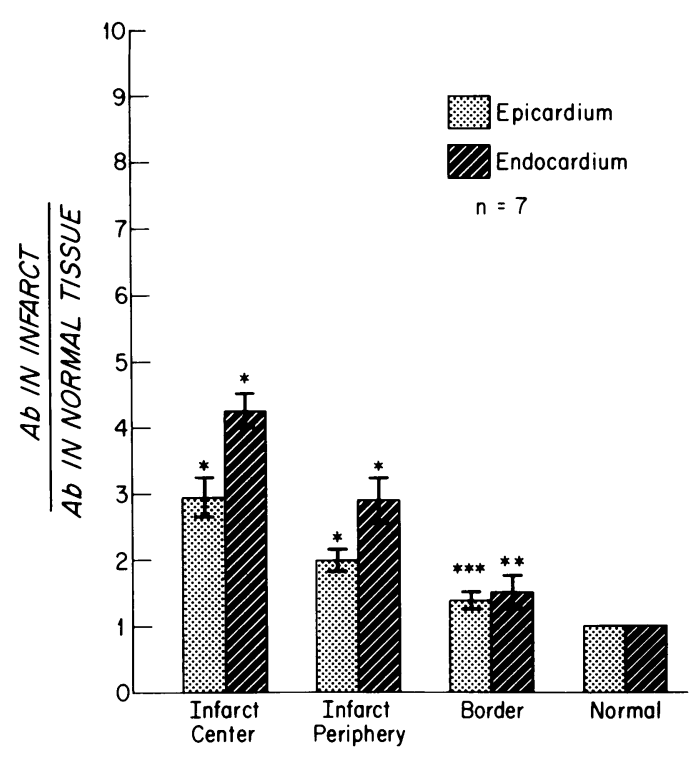

FIgURE 3 Antimyosin antibody binding in infarcted myocardium $24 \mathrm{~h}$ after coronary occlusion. Relative antibody uptake $\left(\left[A b_{I}\right] /\left[A b_{N}\right]\right)$ per gram of endocardial and epicardial layers from infarct center, periphery, border zone region, and normal myocardium of seven dogs is shown. One SEM above and below the mean is depicted at the top of each bar. ${ }^{*} P \leq 0.001 ; * * P<0.01 ; * * * P \leq 0.05$

seven dogs after $24 \mathrm{~h}$ of coronary occlusion is shown in Fig. 3. In the central zone of infarction, the relative antibody uptake was $4.3 \pm 0.4$ (SE) in endocardial and $2.9 \pm 0.3$ in epicardial layers. These ratios were significantly greater than unity, as defined for nonischemic posterior left ventricular myocardium $(P<0.001)$. In the periphery of the infarct zone, the ratio of antibody uptake in this zone to normal myocardial uptake was $2.9 \pm 0.4$ in endocardial and $2.0 \pm 0.2$ in epicardial layers $(P<0.001$ for both values $)$. These ratios were significantly less than those observed in the central infarct zone. Endocardial uptake of antimyosin antibody was significantly greater than the epicardial uptake in both central and peripheral infarct zones.

Localization of ${ }^{125} I$-labeled antimyosin $\left(F a b^{\prime}\right)=$ fragments in infarcted myocardium. To improve the specific uptake of radioiodine-labeled antibody in infarcted as compared to normal myocardium, intravenous doses of ${ }^{125}$ I-labeled antimyosin $\left(\mathrm{Fab}^{\prime}\right)_{2}$ fragments were administered to a group of eight dogs $4 \mathrm{~h}$ after coronary occlusion. Fig. 4 shows relative antimyosin $\left(\mathrm{Fab}^{\prime}\right)_{2}$ uptake in myocardial samples from infarcted and border zone regions in the animals occluded for $24 \mathrm{~h}$. In the infarct center, relative antimyosin $\left(\mathrm{Fab}^{\prime}\right)_{2}$ uptake was $6.0 \pm 0.6$ in endocardial and $3.3 \pm 0.4$ in epicardial layers $(P<0.001$ for both $)$. In the infarct periphery, the ratios for antimyosin $(\mathrm{Fab})_{2}$ uptake were $4.4 \pm 0.4$ in endocardial and $2.4 \pm 0.2$ in epicardial layers $(P<0.001$ for both). Border zone uptake of antimyosin $\left(\mathrm{Fab}^{\prime}\right)_{2}$ was $2.7 \pm 0.5$ in endocardial $(P<0.01)$ and $1.4 \pm 0.4$ in epicardial samples $(P<0.05)$. Antimyosin $\left(\mathrm{Fab}^{\prime}\right)_{2}$ uptake in infarcted and border zone samples was significantly greater than uptake of whole antimyosin antibody as demonstrated in the previous experiments, indicating that the initial rate of antimyosin uptake may depend on the molecular size of the antimyosin preparation employed.

The effect of a longer equilibration time on relative antimyosin $\left(\mathrm{Fab}^{\prime}\right)_{2}$ uptake was investigated in another eight dogs undergoing $72 \mathrm{~h}$ of coronary occlusion before sacrifice. As shown in Fig. 5, the mean ratio of relative antimyosin $\left(\mathrm{Fab}^{\prime}\right)_{2}$ uptake in the center of the infarct was $13.8 \pm 1.2$ in endocardial $(P<0.001)$ and $7.3 \pm 0.8(P<0.001)$ in epicardial samples. Relative antimyosin $\left(\mathrm{Fab}^{\prime}\right)_{2}$ uptake in these 72 -h infarcted dogs was markedly higher than that observed for the 24-h occluded group in both infarcted and border zone regions. As previously observed in dogs receiving whole antimyosin antibody, antimyosin $\left(\mathrm{Fab}^{\prime}\right)_{2}$ fragments localized significantly more in subendocardial than in subepicardial layers.

Comparison of specific localization of antimyosin $\left(F a b^{\prime}\right)$ : components and nonspecific trapping of normal IgG $\left(F a b^{\prime}\right)=$ fragments. Fig. 6 and Table I demonstrate the specific localization of antimyosin $\left(F^{\prime} b^{\prime}\right)_{2}$ fragments in endocardial and epicardial layers of in-

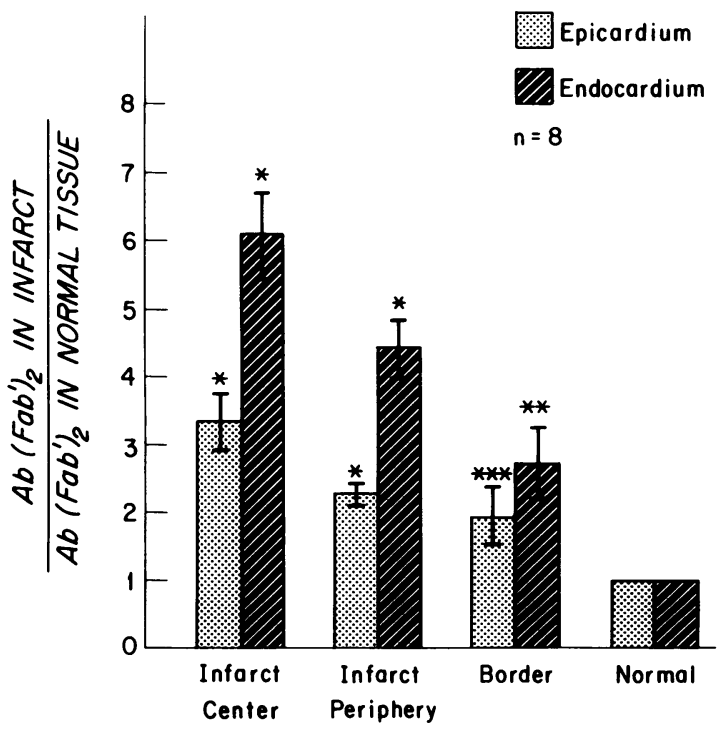

FIgURE 4 Antimyosin $\left(\mathrm{Fab}^{\prime}\right)_{2}$ binding in infarcted myocardium $24 \mathrm{~h}$ after coronary occlusion. Relative antibody uptake $\left[\mathrm{Ab}\left(\mathrm{Fab}^{\prime}\right)_{2} \text { infarct/Ab(Fab' }\right)_{2}$ in normal tissue] in endocardial and epicardial layers of infarct center, periphery, border zone region and normal myocardium of eight dogs is shown. SEM is indicated as in Fig. 3. ${ }^{*} P<0.001$; ${ }^{* * P}$ $<0.005 ; * * * P<0.05$. 


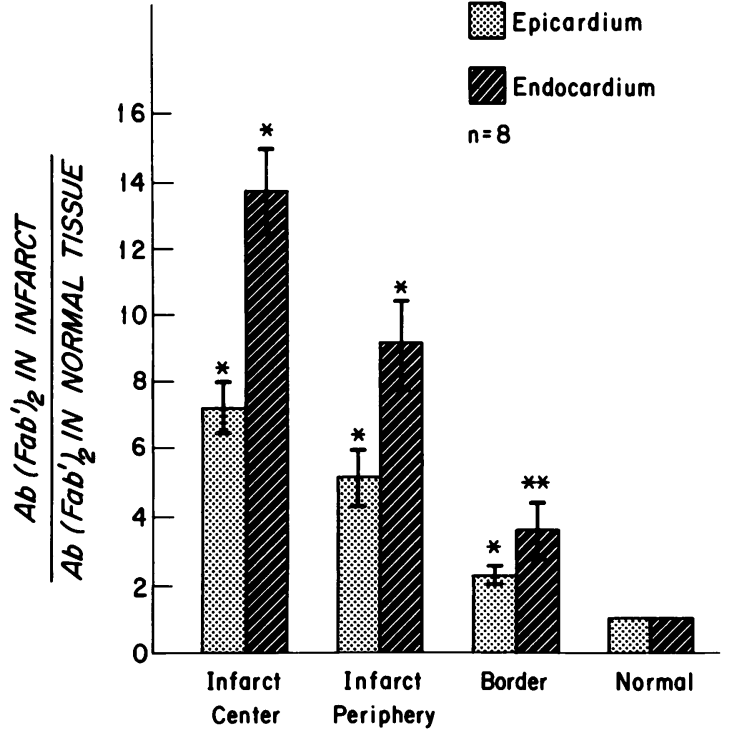

Figure 5 Antimyosin $\left(\mathrm{Fab}^{\prime}\right)_{2}$ binding in infarcted myocardium $72 \mathrm{~h}$ after coronary occlusion. Relative $\mathrm{Ab}\left(\mathrm{Fab}^{\prime}\right)_{2}$ uptake in endocardial and epicardial layers of infarct center, periphery, border zone region, and normal myocardium is shown. SEM indicated as in Fig. 3 . ${ }^{*} P<0.001 ;{ }^{* *} P<0.05$.

farcted myocardium in four dogs receiving both ${ }^{125} \mathrm{I}$ antimyosin $\left(\mathrm{Fab}^{\prime}\right)_{2}$ fragments and ${ }^{131} \mathrm{I}$-normal IgG $\left(\mathrm{Fab}^{\prime}\right)_{2}$ fragments. Nonspecific trapping of $\operatorname{IgG}\left(\mathrm{Fab}^{\prime}\right)_{2}$ was $38 \%$ of the total relative antimyosin $\left(\mathrm{Fab}^{\prime}\right)_{2}$ up-

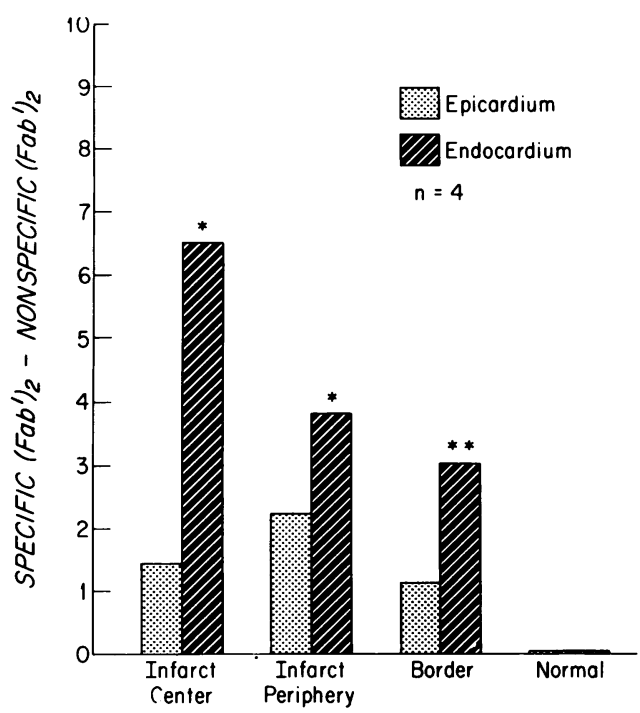

Frgure 6 Specific antimyosin $\left(\mathrm{Fab}^{\prime}\right)_{2}$ binding in infarcted myocardium 48-72 h after coronary occlusion. Specific binding of antimyosin $\left(\mathrm{Fab}^{\prime}\right)_{2}$, obtained by subtracting nonspecific relative localization of normal rabbit IgG $\left(\mathrm{Fab}^{\prime}\right)_{2}$ from relative antimyosin $\left(\mathrm{Fab}^{\prime}\right)_{2}$ binding, in endocardial and epicardial layers of infarct center, periphery, border zone region, and normal myocardium is shown. $* P<0.01$; ${ }^{* *} P$ $<0.05$.
TABLE I

Localization of Antimyosin $\left(F a b^{\prime}\right)_{2}$ Antibody and Normal $\operatorname{IgG}\left(\mathrm{Fab}^{\prime}\right)_{2}$ Injected Simultaneously

\begin{tabular}{llcc}
\hline \multicolumn{1}{c}{ Location } & \multicolumn{1}{c}{$\begin{array}{c}\text { 125I-Antibody } \\
\left(\mathrm{Fab}^{\prime}\right)_{2}\end{array}$} & $\begin{array}{c}\text { 131-Normal Ig } \\
\left(\mathrm{Fab}^{\prime}\right)_{2}\end{array}$ \\
\hline & & $c p m$ & $c$ \\
Posterior left & & & \\
ventricle (normal) & Epi & $336 \pm 11$ & $869 \pm 16$ \\
& Endo & $323 \pm 8$ & $904 \pm 26$ \\
Anterior left & & & \\
$\quad$ ventricle (infarct) & & & \\
Border & Epi & $581 \pm 65$ & $1,196 \pm 12$ \\
& Endo & $1,170 \pm 103$ & $1,853 \pm 172$ \\
Periphery & Epi & $1,570 \pm 117$ & $2,541 \pm 170$ \\
& Endo & $2,505 \pm 33$ & $3,439 \pm 91$ \\
Center & Epi & $1,539 \pm 220$ & $2,398 \pm 167$ \\
& Endo & $3,589 \pm 588$ & $3,828 \pm 80$ \\
\hline
\end{tabular}

take in the center of the infarct zone. Thus, these data indicate that localization of antimyosin $\left(\mathrm{Fab}^{\prime}\right)_{2}$ in infarcted myocardium primarily reflects specific antigenantibody interaction.

Relationship between regional blood flow and antimyosin $\left(F a b^{\prime}\right)=$ uptake in myocardial infarcts. Relative antimyosin $\left(\mathrm{Fab}^{\prime}\right)_{2}$ uptake is represented as a function of regional myocardial blood flow, as determined by distribution of ${ }^{85} \mathrm{Sr}$-microspheres, in Table II. Relative antimyosin $\left(\mathrm{Fab}^{\prime}\right)_{2}$ concentration in dogs after $24 \mathrm{~h}$ of coronary occlusion was $5.0 \pm 0.5$ in myocardial tissue samples where blood flow was reduced to $0-10 \%$ of normal flow. In samples where flow was $11-30 \%$ of normal, the relative antimyosin $\left(\mathrm{Fab}^{\prime}\right)_{2}$ concentration was decreased to $4.0 \pm 0.6$, and in samples where flow was $31-50 \%$ of normal, the relative antibody concentration was only $3.0 \pm 0.3$. These results demonstrate that antimyosin $\left(\mathrm{Fab}^{\prime}\right)_{2}$ uptake was greatest in regions where flow was most severely reduced.

Fig. 7 shows the relationship between regional blood flow and antimyosin $\left(\mathrm{Fab}^{\prime}\right)_{2}$ uptake in four dogs undergoing coronary occlusion for $72 \mathrm{~h}$. An inverse exponential relationship between antimyosin $\left(F^{\prime} b^{\prime}\right)_{2}$ lo-

\section{TABLE II}

Relationship between Antimyosin $\left(F a b^{\prime}\right)_{2}$ Uptake and Regional Blood Flow in Infarcted Myocardium 24 h after Coronary Occlusion

\begin{tabular}{ccccc}
\hline Flow & $1-10$ & $11-30$ & $31-50$ & $51-80$ \\
\hline$\% N$ & & & & \\
{$\left[\mathrm{Ab} \mathrm{b}_{\mathrm{I}}\right]$} & $5.0 \pm 0.5$ & $4.0 \pm 0.6$ & $3.0 \pm 0.3$ & $2.0 \pm 0.1$ \\
\hline$\left[\mathrm{Ab} \mathrm{b}_{\mathrm{N}}\right]$ & & & & \\
\hline
\end{tabular}

I, infarcted myocardium. N, normal myocardium. 


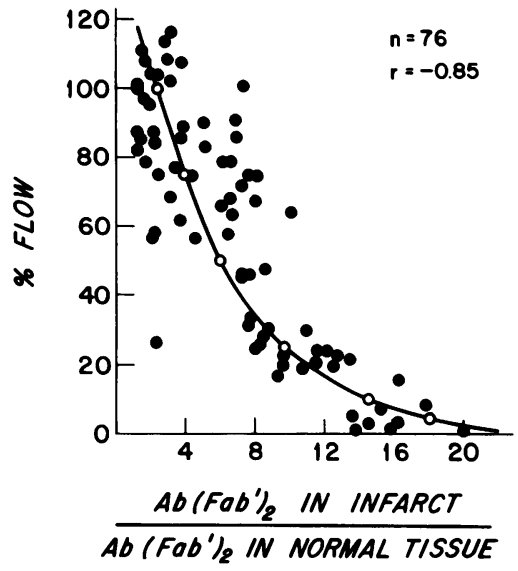

Figure 7 Relationship between antimyosin $\left(\mathrm{Fab}^{\prime}\right)_{2}$ localization in infarcted myocardium and the corresponding regional blood flow $72 \mathrm{~h}$ after coronary occlusion. Relative antimyosin $\left(F_{a b}\right)_{2}$ uptake and regional blood flow for each myocardial tissue sample were determined simultaneously by gamma spectrometry and regional flow plotted against relative antibody uptake. The linear curve (O-O) was obtained by utilizing $y=a+b x$ where $y=\log _{10}$ (\% normal blood flow) and $x=$ relative antimyosin $\left(\mathrm{Fab}^{\prime}\right)_{2}$ uptake.

calization and regional blood flow in the experimentally infarcted myocardium is evident $(r=0.85, P<0,001)$. In tissue samples where flow was reduced to $0-10 \%$ of normal flow, mean relative antimyosin $\left(\mathrm{Fab}^{\prime}\right)_{2}$ uptake was $15.9 \pm 0.8$. In areas where flow was reduced to $11-$ $30 \%$ of normal flow, this ratio was $10.6 \pm 0.7$. The highest antimyosin $\left(\mathrm{Fab}^{\prime}\right)_{2}$ uptake was observed in regions where flow was markedly reduced to $1-2 \%$ of nonischemic myocardial blood flow.

Antimyosin antibody uptake in an uninstrumented animal and in the thoracotomy incision. To determine whether intrinsic differences in antibody uptake occurred between the anterior and posterior walls of the left ventricle, ${ }^{100}$ I-labeled antimyosin antibody was injected intravenously in a normal dog. $24 \mathrm{~h}$ later, the animal was sacrificed and multiple myocardial samples taken. The ratio between anterior and posterior left ventricular counts was $1.0 \pm 0.1$. To determine antibody uptake in the area of a thoracotomy incision, samples of skeletal muscle from this region were taken $24 \mathrm{~h}$ after the injection of labeled antimyosin antibody. The ratio of uptake in this region to normal posterior left ventricular myocardium was $1.7 \pm 0.2$.

\section{DISCUSSION}

The present studies were undertaken to test the hypothesis that macromolecules could enter, as well as exit from, myocardial cells after ischemic damage to membrane permeability, and that macromolecules with appropriate antibody specificity might therefore localize selectively in these damaged areas. Cardiac myosin was chosen as the intracellular component to be studied with regard to specific antibody binding in vivo for the following reasons: $(a)$ it is the major intracellular protein of the cardiac muscle cell $(15) ;(b)$ the high molecular weight $(\simeq 500,000)(16)$ and unique solubility properties of intact myosin suggest that it might remain far longer than other intracellular components in the damaged myocardium; this is supported by persistence of extractable myosin in near-normal concentrations from infarcted tissues up to 30 days after the onset of myocardial infarction (17); and (c) unique structural and antigenic features of cardiac myosin have been demonstrated that are not shared by skeletal and smooth muscle myosin (18).

Utilization of antibodies to localize antigenic determinants has been well established for in vitro studies. Fluorescein-labeled antibodies have been used to detect or localize cell membrane antigens (19) and cell membrane-bound immunoglobulins (20), as well as to delineate intracellular structural components in vitro (21).

The present investigation has demonstrated that antibodies specific for cardiac myosin localized in infarcted myocardium. Specific localization was enhanced by using antimyosin $\left(\mathrm{Fab}^{\prime}\right)_{2}$ fragments that are two thirds the molecular weight of intact antibodies, but retain bivalency of antibody combining sites (22). The use of $\left(\mathrm{Fab}^{\prime}\right)_{2}$ fragments also eliminated the involvement of complement-mediated reactions (23). The data presented are consistent with localization of antibody specific for cardiac myosin (intact or $\left(\mathrm{Fab}^{\prime}\right)_{2}$ ) after the inward diffusion of extracellular macromolecules across membranes altered by ischemic myocardial damage. The presence of intracellular antigen presumably acts as a sink for progressive accumulation of antibody. The specific localization of antimyosin $\left(\mathrm{Fab}^{\prime}\right)_{2}$ in relation to the nonspecific trapping of normal IgG $\left.\left(F_{a b}\right)^{\prime}\right)$ substantiates a specific trapping mechanism based on antigen-antibody interaction. It has been established that after acute myocardial infarction, an increase in permeability of the myocardial cell membrane allows the egress into the plasma of intracellular macromolecular constituents such as creatine phosphokinase (1), serum glutamate oxalacetate transaminase (2), and lactate dehydrogenase (3). The intracellular entry and accumulation of colloidal lanthanum (particle size of $40 \AA$ ) after acute experimental ischemia in dogs also reflects ischemia-induced alteration in membrane permeability (24). Our data establish that after acute myocardial infarction, there is also an inward diffusion of extracellular macromolecules across myocardial cell membranes altered by acute myocardial damage.

The inward diffusion of other macromolecules such as iodine-131-labeled bovine serum albumin ( ${ }^{181} \mathrm{I}-\mathrm{BSA}$ ) 
into damaged myocardium was also observed in two dogs (data not shown). Relative uptake of ${ }^{131}$ I-BSA in the infarcted myocardium was similar to nonspecific localization of ${ }^{131} \mathrm{I}$-normal IgG $\left(\mathrm{Fab}^{\prime}\right)_{2}$, but much less than the uptake of cardiac myosin-specific antibody $\left(\mathrm{Fab}^{\prime}\right)_{2}$ fragments.

Localization of antimyosin $\left(\mathrm{Fab}^{\prime}\right)_{2}$ fragments in infarcted myocardium was also observed to be inversely related to regional blood flow as determined by distribution of ${ }^{85} \mathrm{Sr}$-microspheres. In ischemic myocardial regions where flow was minimally decreased, uptake of antimyosin $\left(\mathrm{Fab}^{\prime}\right)_{2}$ was only slightly above background. With diminishing flow, relative antimyosin $\left(\mathrm{Fab}^{\prime}\right)_{2}$ uptake was observed to increase exponentially. At approximately $2 \%$ of nonischemic myocardial blood flow, maximal antimyosin $\left(\mathrm{Fab}^{\prime}\right)_{2}$ localization was obtained. With the quantity of microspheres used in these studies, no significant alterations in hemodynamics or in regional blood flow to myocardium have been observed (25). Studies employing the microsphere technique to determine regional blood flow in ischemic myocardium in dogs have also shown the reduction of regional flow to be proportional to the severity of myocardial damage (26). Thus, it can be concluded that antimyosin $\left(\mathrm{Fab}^{\prime}\right)_{2}$ localization is greatest in regions where flow was most severely reduced, and where myocardial damage was most extensive.

The data presented in this investigation support the hypothesis that ischemia-induced alteration in myocardial cell membrane permeability that allows the efflux of intracellular macromolecules also permits the influx of extracellular macromolecules to the intracellular space. Antibody specific for cardiac myosin localized selectively and specifically in infarcted myocardium in this in vivo canine experimental model, and the concentration of antimyosin $\left(\mathrm{Fab}^{\prime}\right)_{2}$ fragments increased with increasing severity of myocardial damage and showed an inverse exponential relationship to regional blood flow in infarcted myocardium. These properties suggest that labeled specific antibodies or fragments of antibodies may represent a conceptually new imaging approach to myocardial infarct localization and sizing.

\section{ACKNOWLEDGMENTS}

The authors would like to acknowledge the excellent technical assistance of Richard Moore.

This work was supported in part by U. S. Public Health Service Grant HL-17665 and U. S. PHS Contract 1-HO52992.

\section{REFERENCES}

1. Shell, W. E., J. K. Kjekshus, and B. E. Shell. 1971. Quantitative assessment of the extent of myocardial infarction in the conscious dog by means of analysis of serial changes in serum creatine phosphokinase activity. J. Clin. Invest. 50: 2614.
2. Mydick, I., F. Wroblewski, and J. S. La Due. 1955. Evidence for increased serum glutamic oxalacetic transaminase (SGO-T) activity following graded myocardial infarcts in dogs. Circulation. 12: 161-168.

3. Sobel, B. E., and W. E. Shell. 1972. Serum enzyme determinations in the diagnosis and assessment of myocardial infarction. Circulation. 45: 471-482.

4. Jennings, R. B., W. B. Wartman, and G. W. Smethers. 1957. Studies on distribution and localization of potassium in early myocardial ischemic injury. Arch. Pathol. 63: $586-592$.

5. Katz, A. M., I. Doris, C. T. Repke, and B. B. Rubin. 1965. Adenosine-triphosphate activity of cardiac myosin. Circ. Res. 19 : 611-620.

6. Wikman-Coffelt, J., R. Zelis, C. Fenner, and D. T. Mason. 1973. Myosin chains of myocardial tissue. I. Purification and immunological properties of myosin heavy chains. Biochem. Biophys. Res. Commun. 51: 1097-1104.

7. Neville, D. M., Jr. 1971. Molecular weight determination of protein-dodecyl sulfate complexes by gel electrophoresis in a discontinuous buffer system. J. Biol. Chem. 246: $6328-6334$.

8. Lawrence, D. A., M. J. Tye, and M. Liss. 1972. Immunochemical analysis of the basic immunoglobulin in papular mucinosis. Immunochemistry. 9: 41-49.

9. Ouchterlony, O. 1953. Antigen-antibody reactions in gels. Acta. Pathol. Microbiol. Scand. 32 : 231-240.

10. Marchalonis, J. J. 1969. An enzymatic method for the trace iodination of immunoglobulins and other proteins. Biochem. J. 11.3 : 299-305.

11. Cuatrecasas, P. 1970. Protein purification by affinity chromatography. Derivation of agarose and polyamide beads. J. Biol. Chem. 245: 3059-3065.

12. Edelman, G. M., and J. J. Marchalonis. 1967. Methods in immunology and immunochemistry. Vol. I. Preparation of antigens and antibodies. Ed. Williams and Chase. Academic Press, Inc., New York. 422-423.

13. Beller, G. A., T. W. Smith, and W. B. Hood, Jr. 1972. Altered distribution of titrated digoxin in the infarcted canine left ventricle. Circulation. 46: 572.

14. Snedecor, G. W., and W. J. Cochran. 1971. Statistical Methods. Iowa State University Press, Ames, Iowa. 95, 135-171.

15. Katz, A. M. 1970. Contractile proteins of the heart. Physiol. Rev. 50: 63-158.

16. Luchi, R. J., E. M. Kritcher, and H. L. Conn, Jr. 1965. Molecular characteristics of canine cardiac myosin. Circ. Res. 16: 74-82.

17. Fetisova, T. V., and I. P. Zabolotnyuk. 1965. Changes in heart muscle and liver proteins in experimental myocardial infarction. Fed. Proc. 24: T960-T962.

18. Finck, H. 1965. Immunochemical studies of myosin. III. Immunochemical comparison of myosins from chicken skeletal, heart and smooth muscle. Biochim. Biophys. Acta. 111 : 231-238.

19. Lender, E., A. Vaheri, E. Ryoslahti, and J. Wartiovaara. 1975. Distribution of fibroblast surface antigen in the developing chick embryo. J. Exp. Med. 142: 41-49.

20. Zucker-Franklin, D., and S. Berney. 1972. Electron microscope study of surface immunoglobulin-bearing human tonsil cells. J. Exp. Med. $135: 533-548$.

21. Lazarides, E., and K. Weber. 1974. Actin antibody: the specific visualization of actin filaments in non-muscle cells. Proc. Natl. Acad. Sci. U. S. A. 71: 2268-2272. 
22. Jaquet, H., and J. J. Cebra. 1965. Comparison of two precipitating derivatives of rabbit antibody: fragment I dimer and the product of pepsin digestion. Biochemistry. 4: $954-963$.

23. Taranta, A., and E. C. Franklin. 1961. Complement fixation by antibody fragments. Science (Wash. D. C.). 131: 1981-1982.

24. Hoffstein, S., D. E. Gennaro, A. C. Fox, J. Hirsch, F. Streuli, and G. Weissman. 1975. Colloidal lanthanum as a marker for impaired plasma membrane permeability in ischemic dog myocardium. Am. J. Pathol. 79: 207218.

25. Fortuin, N. J., S. Kaihara, L. C. Becker, and B. Pitt. 1971. Regional myocardial blood flow in the dog studied with radioactive microspheres. Cardiovasc. Res. 5: 331336.

26. Becker, L. C., R. Ferreira, and M. Thomas. 1973. Mapping of left ventricular blood flow with radioactive microspheres in experimental coronary artery occlusion. Cardiovasc. Res. 7 : 391-400. 